\title{
Salmonella enterica serovar Typhimurium sseK3 induces apoptosis and enhances glycolysis in macrophages
}

\section{Chuan Yu}

Henan University of Science and Technology

\section{Fuyu Du}

Henan University of Science and Technology

Chunjie Zhang ( $\nabla$ cjzhang@sina.com )

https://orcid.org/0000-0002-4079-8091

\section{Yinju Li}

Henan University of Science and Technology

\section{Chengshui Liao}

Henan University of Science and Technology

Lei He

Henan University of Science and Technology

\section{Xiangchao Cheng}

Henan University of Science and Technology

\section{Xiaojie Zhang}

Henan University of Science and Technology

\section{Research article}

Keywords: S. Typhimurium, sseK3, macrophages apoptosis, glycolysis

Posted Date: May 13th, 2020

DOI: https://doi.org/10.21203/rs.2.17312/v3

License: (c) (1) This work is licensed under a Creative Commons Attribution 4.0 International License. Read Full License

Version of Record: A version of this preprint was published at BMC Microbiology on June 9th, 2020. See the published version at https://doi.org/10.1186/s12866-020-01838-z. 


\section{Abstract}

Background: Salmonella enterica serovar Typhimurium (S. Typhimurium) is an important infectious disease pathogen that can survive and replicate in macrophages. Glycolysis is essential for immune responses against $S$. Typhimurium infection in macrophages, and is also associated with apoptosis. $S$. Typhimurium secreted effector K3 (SseK3) was recently identified as a novel translated and secreted protein. However, there is no study about the role of $s s e K 3$ in the relationship between apoptosis and glycolysis in cells infected with $S$. Typhimurium. It is unclear whether this protein exerts a significant role in the progress of apoptosis and glycolysis in $S$. Typhimurium-infected macrophages.

Results: Macrophages were infected with S. Typhimurium SL1344 wild-type (WT), $\Delta$ sseK3 mutant or sseK3-complemented strain, and the effects of $s s e K 3$ on apoptosis and glycolysis were determined. The adherence and invasion in the $\Delta s s e K 3$ mutant group were similar to that in the WT and sseK3complemented groups, indicating that SseK3 was not essential for the adherence and invasion of $S$. Typhimurium in macrophages. However, the percentage of apoptosis in the $\Delta s s e K 3$ mutant group was much lower than that in the WT and sseK3-complemented groups. Caspase-3, caspase-8, and caspase-9 enzyme activity in the $\Delta$ sseK3 mutant group were significantly lower than in the WT group and sseK3complemented groups, indicating that $s s e K 3$ could improve the caspase-3, caspase- 8 , and caspase- 9 enzyme activity. We also found that there were no significant differences in pyruvic acid levels between the three groups, but the lactic acid level in the $\Delta s s e K 3$ mutant group was much lower than that in the WT and sseK3-complemented groups. The ATP levels in the $\Delta s s e K 3$ mutant group were remarkably higher than those in the WT and sseK3-complemented groups. These indicated that the sseK3 enhanced the level of glycolysis in macrophages infected by $S$. Typhimurium.

Conclusions: $S$. Typhimurium sseK3 is likely involved in promoting macrophage apoptosis and modulating glycolysis in macrophages. Our results could improve our understanding of the relationship between apoptosis and glycolysis in macrophages induced by $S$. Typhimurium sseK3.

\section{Background}

Salmonella enterica serovar Typhimurium (S. Typhimurium) is a zoonotic pathogen that can infect humans [1]. Salmonella can be transmitted to humans via contaminated animal products, causing illness and potentially deaths $[1,2]$. $S$. Typhimurium can survive and replicate in macrophages, which could carry bacteria from the Peyer's patches to adjacent lymph nodes, the spleen and the liver in mouse models [3].

Glycolysis is an essential cellular metabolic pathway [4]. Under anaerobic conditions, the pyruvate is eventually converted into lactic acid. However, under aerobic conditions, pyruvic acid enters the tricarboxylic acid cycle (TCA cycle) and is oxidized to $\mathrm{CO}_{2}$ and $\mathrm{H}_{2} \mathrm{O}$ [5]. Apoptosis is closely associated with glycolysis activities [6, 7]. Inhibition of the glycolysis with iodoacetate was associated with macrophage apoptosis[8], and genetic silencing of hypoxia inducible factor-1a (HIF-1a) repressed imiquimod-induced aerobic glycolysis and sensitized cells to imiquimod-induced apoptosis owing to 
faster ATP and Mcl-1 depletion [6]. Sirtuin 6 modulates hypoxia-induced apoptosis in osteoblasts via inhibition of glycolysis, and hypoxia-induced apoptosis of osteoblasts is dependent on glycolytic activity [9]. Several molecules that function intracellularly as enzymes are involved in glycolysis, and become externalized to the surface of apoptotic cells, causing apoptotic recognition and the triggering innate apoptotic immunity [10]. Thus, glycolysis is closely related to apoptosis.

Immune cells were able to detect the metabolic abnormalities caused by Salmonella through inflammatory signals, and glycolysis was essential for this process in $S$. Typhimurium-infected with macrophages [11, 12]. Salmonella pathogenicity island 2 (SPI-2)-encoded type III secretion system 2 (T3SS2), which delivers 28 effector proteins into the host cell, is one of the key virulence determinants after invasion or phagocytic uptake of Salmonella [13-15]. Previous studies have identified that Salmonella secreted effector K3 (SseK3) is a novel translated and secreted protein of S. Typhimurium, and is encoded by the sseK3 gene [16]. SseK3 is a glycosyltransferase, and could transfer an N-acetylglucosamine moiety onto the guanidino group of a target arginine, thereby regulating host cell function [17]. It belongs to the glycosyltransferase type-A family of glycosyltransferase enzymes and binds ligands in a metal-ion-dependent manner via a DXD motif [17]. SseK3 is co-regulated with the T3SS2 in host cells and is injected into infected host cells [18]. However, the mechanisms underlying SseK3 activity during S. Typhimurium infection and the role of sseK3 in macrophage glycolysis remain unclear.

In this study, we aimed to determine the role of $S$. Typhimurium sseK3 on macrophage apoptosis and glycolysis after $S$. Typhimurium infection. Our data showed that the $s s e K 3$ of $S$. Typhimurium could promote macrophage apoptosis and improve glycolysis levels. These results would provide a better understanding of the relationship between glycolysis and apoptosis in $S$. Typhimurium-infected macrophages.

\section{Results}

\section{Adherence and invasion}

The invasive and adhesive abilities of the sseK3 mutant and complemented strain were similar to those of the WT strain (Supplementary Fig.1A, Fig.1B); there were no significant differences between the WT, $\triangle$ sseK3 mutant, and sseK3-complemented groups $(P>0.05)$. This suggests that $s s e K 3$ does not play a prominent role in promoting the attachment and invasion of $S$. Typhimurium into the macrophages. Because the same number of bacteria invaded macrophages of the different infection groups, the intracellular load was consistent, and improved the accuracy of subsequent experiments.

\section{Apoptosis}

Apoptosis assays were performed as previously described $[19,20]$. The percentage of apoptotic cells of $\triangle$ sseK3 mutant group was much lower than that in the WT and sseK3-complemented groups. In the $\Delta$ sseK3 mutant group, the percentage of FITC-Annexin V positive cells was $3.78 \%$, while in the WT group, 
it was $14.64 \%$ (Fig.1), suggesting that SseK3 plays an important role in S. Typhimurium-induced macrophage apoptosis.

\section{Caspase activity}

Caspases play an essential role in apoptosis [21]. Caspase-3, 8, and 9 activity was therefore measured at different time points (Fig.2), and was much lower in the mock group than in the infection groups ( $\Delta s s e K 3$ mutant, WT, and sseK3-complemented groups), indicating that $S$. Typhimurium infection could stimulate the activity of caspase-3, 8, and 9 in macrophages. However, it could be seen from Fig. 2 that caspase-8 and caspase- 9 activity was significantly lower in the $\Delta s s e K 3$ mutant group than that in the WT and sseK3-complemented groups at $2 \mathrm{~h}, 4 \mathrm{~h}, 6 \mathrm{~h}$, and $8 \mathrm{~h}(P<0.001)$, suggesting that SseK3 could induce the activation of caspase-8 and caspase- 9 . There was no significant difference in caspase- 3 activity among the $\Delta$ sseK3 mutant, WT, and sseK3-complemented groups at $2 \mathrm{~h}(P>0.05)$. However, significant differences in caspase- 3 activity were observed among the infection groups at $4 \mathrm{~h}, 6 \mathrm{~h}$, and $8 \mathrm{~h}(P<$ $0.001)$. Caspase 3 activity was significantly lower in the $\Delta s s e K 3$ mutant group than in the WT and sseK3complemented groups. These results illustrated that SseK3 likely played a pivotal role in the process of inducing macrophage apoptosis by $S$. Typhimurium.

\section{Glycolysis}

To determine whether SseK3 could affect glycolysis in macrophages infected with $S$. Typhimurium, pyruvic acid, lactic acid, and ATP levels were detected as previously described [22-24] (Fig.3). The results showed that there were no significant differences in pyruvic acid levels between different groups at $2 \mathrm{~h}, 4$ $\mathrm{h}, 6 \mathrm{~h}$, and $8 \mathrm{~h}(P>0.05)$. However, there were significant differences in lactic acid levels between the mock and infection groups at $2 \mathrm{~h}, 4 \mathrm{~h}, 6 \mathrm{~h}$, and $8 \mathrm{~h}(P<0.001)$. Macrophages glycolysis was significantly increased in the infection groups than in the mock group, and lactic acid levels were significantly lower in the $\Delta$ sseK3 mutant group than in the WT and sseK3-complemented groups at $4 \mathrm{~h}, 6 \mathrm{~h}$, and $8 \mathrm{~h}(P<$ 0.001). The investigations of glycolysis in macrophages suggested that SseK3 encoded by sseK3 could boost lactic acid levels in macrophages. Further, ATP levels were significantly lower in infection groups than in the mock group at $4 \mathrm{~h}, 6 \mathrm{~h}$, and $8 \mathrm{~h}(P<0.001)$, and much higher in the $\Delta s s e K 3$ mutant group than in the WT and sseK3-complemented groups at $4 \mathrm{~h}, 6 \mathrm{~h}$, and $8 \mathrm{~h}(P<0.001)$. These results illustrated that SseK3 encoded by sseK3 could improve glycolysis in macrophages by modulating lactic acid and the ATP levels.

\section{Discussion}

Many Salmonella secreted proteins exert different virulence functions in the process of bacterial survival and replication in host cells [25]. In Salmonella SCVs T3SS2 helps Salmonella transport virulence (effector) proteins into host cells [26]. S. Typhimurium expresses the SseK family of proteins, including SseK1, SseK2 and SseK3, which are T3SS effectors [1,27]. SseK3 is essential for cellular Salmonella infection, and plays a pivotal role in the natural host immune process $[16,18]$. Several secretory proteins of $S$. Typhimurium contribute to the considerable stress observed during apoptosis $[25,26,28,29]$. There 
were several studies about the function of SseK3. Joshua et al found that SseK3 targeted death domain proteins in the TNF and TRAIL signaling pathways and employed the glycosyltransferase effectors to antagonize different components of death receptor signaling [30]. Yang et al found that SseK3 could bind an E3 ubiquitin ligase (TRIM32) and influence NF-KB activity [16]. But Günster et al found that SseK3 caused weak GlcNAcylation of TNFR1-associated death domain protein (TRADD) and inhibited TNF-ainduced apoptosis in Salmonella-infected macrophages [26]. These researches were contradictory. Nonetheless, there has been no research on the role of SseK3 in the relationship between apoptosis and glycolysis in Salmonella-infected macrophages. To our knowledge, this is the first study to determine the effect of $S$. Typhimurium SseK3 encoded by $s s e K 3$ on macrophage glycolysis during $S$. Typhimuriuminduced apoptosis.

Santo et al found that early sipB-dependent and delayed sipB-independent mechanisms could cause the apoptosis induced by $S$. Typhimurium [31]. Further, $S$. Typhimurium without ribose chemoreceptors localized in tumor quiescence and induced apoptosis [32]. Moreover, research had shown that the cAMP receptor protein of $S$. Typhimurium could induce the macrophage apoptosis [33]. Based on previous functional studies of Salmonella genes in macrophages [16, 26, 34-36], we used the WT, $\Delta$ sseK3 mutant, and sseK3-complemented strains to infect the macrophages to determine the relationship between $S$. Typhimurium sseK3 and macrophages apoptosis. We found that the adherence and invasion percentages in the $\triangle$ sseK3 mutant group were similar to those of WT group and sseK3-complemented group during the infecting period $(P>0.05)$, which confirmed that the WT, $\Delta$ sseK3 mutant, and sseK3complemented strains had the same level going through into the macrophages. Subsequently, the apoptosis in different infection groups were detected by the assay of flow cytometry. The percentage of apoptotic cells in the $\Delta s s e K 3$ mutant group (3.78\%) was much lower than that in the WT $(14.64 \%)$ and sseK3-complemented (11.81\%) groups, indicating that deletion of the sseK3 gene significantly affected host cell apoptosis.

The activation of caspases is essential for apoptosis induced by loss of the mitochondria membrane [37]. SopB of Salmonella could protect the host cell from caspase-3-induced apoptosis [38]. Activation of caspase- 3 and caspase -9 indicated that apoptosis was activated in macrophages infected by Escherichia coli [39]. Further, caspase-8 influenced the synthesis of pro-IL-1 $\beta$ and was essential for apoptosis induced by Salmonella [40]. In this study, we found that caspase-3, caspase- 8 and caspase-9 activity was significantly higher in the infection groups than in the mock group at $2 \mathrm{~h}, 4 \mathrm{~h}, 6 \mathrm{~h}$, and $8 \mathrm{~h}(P<0.001)$, indicating that apoptosis was activated in the infected macrophages. Furthermore, the caspase- 3 , caspase- 8 and caspase- 9 activity was much lower in the $\Delta s s e K 3$ mutant group than in the WT and sseK3-complemented groups, which suggested that SseK3 may be a pivotal component for $S$. Typhimurium activating apoptosis in macrophages. In our previous studies, we found that disruption of sseK3 could reduce the virulence of $S$. Typhimurium ( $\mathrm{Du}$, et al. in press). We further speculated that the Ssek3-mediated activation of apoptosis in macrophages may affect the virulence of $S$. Typhimurium.

Apoptosis and glycolysis are closely related. Comin-Anduix et al found that fermented wheat germ extract (FWGE) inhibited glycolysis and induced apoptosis in tumor cells [41]. Jeong et al found that the 
modification of glycolysis could change the sensitivity of apoptosis via the mitochondrial pathway [42]. Recently, research has shown that inhibition of glycolysis could block cell apoptosis [43]. Methyl jasmonate could inhibit the glycolysis and induce apoptosis of tumor cells [44], whereas propofol could improve glycolysis of cells and cause the apoptosis [45]. Pyruvic acid, lactic acid and ATP are important components in the process of cellular glycolysis. Various metabolic pathways produce pyruvic acid [46]. Pyruvic acid could enter the TCA cycle and be completely oxidized in aerobic conditions, or could become lactic acid under anaerobic conditions $[47,48]$. HIF-1 a could prevent the production of ATP and thus regulate the glycolysis of mouse granulosa cells [49]. We studied glycolysis in macrophages infected with WT, $\Delta$ sseK3 mutant, or sseK3-complemented by detecting the levels of pyruvic acid, lactic acid, and ATP. There were no significant differences in intracellular pyruvic acid levels among the groups $(P>0.05)$. Compared to the WT and sseK3-complemented groups, the lactic acid levels of microphages infected by $\triangle$ sseK3 mutant strain did not significantly change at $2 \mathrm{~h}(P>0.05)$. However, there were significant differences between the WT and $\triangle$ sseK3 mutant groups at $4 \mathrm{~h}(P<0.001), 6 \mathrm{~h}(P<0.001)$, and $8 \mathrm{~h}(P<$ $0.001)$, suggesting that the deletion of $s s e K 3$ may reduce $S$. Typhimurium-induced glycolysis in macrophages, and SseK3 likely enhances glycolysis. Furthermore, lactic acid levels were significantly higher in the WT, $\Delta$ sseK3 mutant, and sseK3-complemented strains, than in the mock group $(P<0.001)$, which illustrated that the anaerobic pathway was enhanced in macrophages of the infection groups. There was no significant difference in ATP levels among the groups at $2 \mathrm{~h}$; however, the ATP levels were significantly higher in the $\Delta$ sseK3 mutant group than in the WT and sseK3-complemented groups at $4 \mathrm{~h}$ $(P<0.001), 6 \mathrm{~h}(P<0.001)$, and $8 \mathrm{~h}(P<0.001)$, indicating that glycolysis was lower in the WT and sseK3complemented groups than in the $\Delta$ sseK3 mutant group, and SseK3 likely enhanced glycolysis. Moreover, the ATP levels of macrophages in the mock group were significantly higher than those in the infections groups at $4 \mathrm{~h}(P<0.001), 6 \mathrm{~h}(P<0.001)$, and $8 \mathrm{~h}(P<0.001)$, which suggested that aerobic metabolism was predominant in the mock group, since less ATP is produced by glycolysis than by aerobic oxidation. Therefore, the deletion of sseK3 likely decreased glycolysis in the $\Delta s s e K 3$ group compared with WT group, and SseK3 could improve glycolysis in macrophages infected by $S$. Typhimurium and thereby induce apoptosis. This conclusion was consistent with the results of Sumi et al' [45] and Ding et al' [33], showing that glycolysis and apoptosis of cells could be improved simultaneously. But it was not in agreement with the findings of Li et al' [44] and Comin-Anduix et al' [41], who showing that glycolysis of cells was inhibited and apoptosis of cells was enhanced, possible owing to differences in the type of cell. Glycolysis is the main source of energy in cancer cells, which use this metabolic pathway for ATP generation. Altered energy metabolism is a biochemical fingerprint of cancer cells, and is a "hallmark of cancer" [50]. Rosmarinic acid induces apoptosis in HepG2 cells, mainly via inactivation of the glycolytic pathway [51]. However, macrophages show a high level of plasticity, with the ability to undergo dynamic transition between M1 and M2 polarized phenotypes [52]. Lipopolysaccharide (LPS) of bacteria could induce RAW264.7 macrophages into the classical proinflammatory injury phenotype (M1) [53]. Activation of inflammatory responses could cause the apoptosis by mediating inactivation of the PI3K/Akt/GSK-3 $\beta$ signaling pathway [54]. Moreover, the proinflammatory stimulus, LPS, suppresses myelocytomatosis viral oncogene (Myc) expression and cell proliferation and engages a HIF1a-dependent transcriptional program responsible for heightened glycolysis [55]. We speculate that $S$. Typhimurium Ssek3 might 
activate the M1 phenotype of macrophages and thereby activate HIF1a, which enhances glycolysis and finally causes apoptosis. There could be several different signaling pathways involved in Ssek3-mediated apoptosis and glycolysis of macrophages, which merit further study. We aim to further clarify the relationship between glycolysis and apoptosis in future studies.

\section{Conclusions}

Our results cumulatively showed that SseK3 of $S$. Typhimurium could induce apoptosis and improve glycolysis in macrophages. Our findings may help to illustrate the mechanism by which $S$. Typhimurium induces macrophage apoptosis and provide a better understanding of the putative relationship between SseK3-induced macrophage apoptosis and glycolysis.

\section{Methods}

\section{Bacterial strains, cells, and culture}

S. Typhimurium SL1344, Typhimurium SL1344 $\Delta$ sseK3 mutant (with deletion of sseK3), and sseK3complemented bacterial strains used in this study were available in our laboratory. The $\Delta$ sseK3 mutant was constructed using counter-selectable suicide vectors. The sseK3 gene was cloned into the pBR322 plasmid for complementation studies. RAW264.7 macrophage cells were obtained from the American type culture collection (ATCC, Manassas, VA), and cultured in Dulbecco's modified Eagle medium (DMEM)/high-glucose medium (HyClone, USA) containing 10\% fetal calf serum (FCS) in an incubator at $37^{\circ} \mathrm{C}$ and $5 \% \mathrm{CO}_{2}$.

\section{Adherence and invasion assay}

Adhesion and invasion of RAW264.7 cells was assessed as previously described [56, 57]. A 24-well cell culture plate was inoculated with $1 \times 10^{5}$ RAW264.7 cells per well. The WT, $\Delta$ sseK3 mutant and sseK3complemented strains were then added to RAW264.7 cells at a multiplicity of infection (MOI) of 100:1, with three replicate wells per strain. To allow complete contact between the bacteria and RAW264.7 cells, the plates were centrifuged at $1000 \mathrm{rpm}$ and incubated in $5 \% \mathrm{CO}_{2}$ for $2 \mathrm{~h}$ at $37{ }^{\circ} \mathrm{C}$. For the adherence assay, the supernatants were aspirated, and the cells were washed three times with PBS. Subsequently, the cells were digested with $0.25 \%$ trypsin, plated in a gradient dilution and counted. For the invasion assay, the supernatants were aspirated, cells were washed three times with PBS, gentamicin-containing medium $(100 \mu \mathrm{g} / \mathrm{mL})$ was added, and the cells were incubated at $37{ }^{\circ} \mathrm{C}$ with $5 \% \mathrm{CO}_{2}$. After incubation, the supernatants were aspirated, and the cells were washed three times with PBS. Subsequently, the cells were lysed using $0.1 \%$ Triton X-100, plated with a gradient dilution and counted.

\section{Flow cytometry assay}

A 6-well cell culture plate was inoculated with $1 \times 10^{6}$ RAW264.7 cells per well and incubated for $16 \mathrm{~h}$. WT, $\Delta$ sseK3 mutant and sseK3-complemented strains were incubated with RAW264.7 cells at a multiplicity of 
infection (MOI) of 100:1, with three replicate wells per strain. To allow complete contact between bacteria and RAW264.7 cells, the plates were centrifuged at $1000 \mathrm{rpm}$. Gentamicin-containing medium (100 $\mu \mathrm{g} / \mathrm{mL}$ ) was then added and the plates incubated at $37{ }^{\circ} \mathrm{C}$ with $5 \% \mathrm{CO}_{2}$. After incubation, the supernatants were aspirated, and the cells were washed three times with PBS. The percentage of cells undergoing apoptosis was detected by flow cytometry using an Annexin V-FITC/PI apoptosis detection kit (KeyGEN BioTECH, Jiangsu, China). Cells from the infected and mock groups were digested with $0.25 \%$ trypsin, washed three times with ice-cold phosphate buffered saline (PBS), and suspended in $500 \mu \mathrm{L}$ binding buffer. $5 \mu \mathrm{L}$ Annexin V-FITC and $5 \mu \mathrm{L}$ Propidium lodide (PI) were added, and the solution was incubated in a dark room for 15 min at room temperature and immediately analyzed by flow cytometry (Beckman Coulter, Inc., Fullerton, CA, US).

\section{Caspase-3, caspase-8, and caspase-9 activity assay}

Caspase-3, caspase-8, and caspase-9 activity was measured using a Caspase-3 Assay Kit, Caspase-8 Assay Kit, and Caspase-9 Assay Kit (Beyotime, Shanghai, China), respectively. A 6-well cell culture plate was inoculated with $1 \times 10^{6}$ RAW264.7 cells per well and incubated for $16 \mathrm{~h}$. WT, $\Delta$ sseK3 mutant, and sseK3-complemented strains were incubated with the RAW264.7 cells at a MOI of 100:1, with three replicate wells per strain. The plates were centrifuged at $1000 \mathrm{rpm}$ and gentamicin-containing medium $(100 \mu \mathrm{g} / \mathrm{mL})$ was added and incubated at $37{ }^{\circ} \mathrm{C}$ with $5 \% \mathrm{CO}_{2}$. The supernatants were then aspirated, and the cells were washed three times with PBS. Subsequently, the cells of the infected and mock groups were digested by trypsinization without EDTA and washed three times with ice-cold lysis buffer, and treated with $100 \mu \mathrm{L}$ lysis buffer on ice. After incubation for 15 minutes, the concentration of protein was detected using the Bradford protein assay kit (Beyotime, Shanghai, China). Subsequently, the cell lysates were incubated with Ac-DEVD-pNA for $4 \mathrm{~h}$ at $37^{\circ} \mathrm{C}$, the absorbance was read at $405 \mathrm{~nm}$ in a microplate spectrophotometer (Infinite 200 PRO NanoQuant, Tecan, Switzerland).

\section{Glycolysis assay}

The glycolysis levels were measured using pyruvic acid, lactic acid, and ATP analysis kits, which were purchased from Nanjing Jiancheng Bioengineering Institute (Nanjing, China). WT, $\Delta s s e K 3$ mutant, and sseK3-complemented groups were treated as above similar methods. After incubation with gentamicincontaining medium $(100 \mu \mathrm{g} / \mathrm{mL})$, the supernatants were aspirated, and the cells were washed three times with PBS. Cells were then analyzed using the kits according to manufacturers' instructions at $2 \mathrm{~h}, 4 \mathrm{~h}, 6 \mathrm{~h}$, and $8 \mathrm{~h}$. The protein concentration in each group was detected using the Bradford protein assay kit (Beyotime, Shanghai, China), and absorbance values for pyruvic acid analysis, lactic acid, and ATP analysis were read at $505 \mathrm{~nm}, 530 \mathrm{~nm}$, and $636 \mathrm{~nm}$, respectively in a microplate spectrophotometer (Infinite 200 PRO NanoQuant, Tecan, Switzerland).

\section{Statistical analysis}

Data were presented as the mean \pm standard deviation (SD) of three independent experiments. Two-way analysis of variance (ANOVA) with a post-hoc test (Bonferroni's multiple-comparison test) was used to 
compare and assess statistical significance among all groups. $P<0.05$ was considered statistically significant.

\section{Declarations}

\section{Ethics approval and consent to participate}

Not applicable.

\section{Consent for publication}

Not applicable.

\section{Availability of data and materials}

The data generated and/or analyzed during the current study are available from the corresponding author on reasonable request.

\section{Competing interests}

The authors declare that they have no competing of interests.

\section{Funding}

This study was funded by grants from National Natural Science Foundation of China (31572489), the National Natural Science Foundation of Henan (182300410078), Henan Science and Technology Key Project (182102110061).

\section{Authors' contributions}

$\mathrm{CY}$ and FD contributed equally to this work. They performed the experiments, analyzed the experimental results and wrote manuscript. $\mathrm{FD}, \mathrm{CY}$, and $\mathrm{CZ}$ conceived of and designed the experiments. $\mathrm{FD}, \mathrm{CY}, \mathrm{CZ}$, and $Y L$ analyzed experiment performance. $C L, L H$, and $X C$ analyzed and interpreted all of the data. $Y L, C L, L H$, and $\mathrm{XZ}$ performed the statistical analyse. $\mathrm{CY}, \mathrm{CZ}, \mathrm{YL}$, and $\mathrm{XC}$ did the supervised study. All authors read and approved the manuscript.

\section{Acknowledgements}

We thank Roy Curtiss III (at the Department of Biology, Washington University, St. Louis, MO) for the generous donation of strains and plasmids. We thank Beyotime (https://www.beyotime.com/support/Thesis.htm) for editing the English text of a draft of this manuscript.

\section{Authors' Information}


Chuan $\mathrm{Yu}^{1,2,3 \dagger}$, Fuyu Du ${ }^{1,2 \dagger}$, Chunjie Zhang ${ }^{1,2 *}$, Yinju Li ${ }^{1,2}$, Chengshui $\mathrm{Liao}^{1,2}$, Lei He ${ }^{1,2}$, Xiangchao Cheng ${ }^{1,2,3}$, Xiaojie Zhang ${ }^{1,2}$

Chuan Yu and Fuyu Du contributed equally to this work. Chunjie Zhang is the corresponding author.

Affiliations:

${ }^{1}$ The Key Lab of Animal Disease and Public Health, Henan University of Science and Technology, 263 Kaiyuan Avenue, Luoyang 471023, Henan, China

${ }^{2}$ Luoyang Key Laboratory of Live Carrier Biomaterial and Animal Disease Prevention and Control, Luoyang 471023, Henan, China

${ }^{3}$ Luoyang Polytechnic, 6 Airport Road, Luoyang 471023, Henan, China

\section{References}

1. Zhang X, He L, Zhang C, Yu C, Yang Y, Jia Y, Cheng X, Li Y, Liao C, Li J et al: The impact of sseK2 deletion on Salmonella enterica serovar typhimurium virulence in vivo and in vitro. BMC Microbiol 2019, 19(1):182.

2. Kalaba V, Golić B, Ž Sladojević, Kalaba D: Incidence of Salmonella Infantis in poultry meat and products and the resistance of isolates to antimicrobials. IOP Conference Series: Earth and Environmental Science 2017, 85:012082.

3. Vazquez-Torres A, Jones-Carson J, Bäumler AJ, Falkow S, Valdivia R, Brown W, L M, Berggren R, Parks W T, Fang F C: Extraintestinal dissemination of Salmonella by CD18-expressing phagocytes. Nature 1999, 401(6755):804-808.

4. Planqué $R$, Bruggeman FJ, Teusink $B$, Hulshof $\mathrm{J}$ : Understanding bistability in yeast glycolysis using general properties of metabolic pathways. Math Biosci 2014, 255(1):33-42.

5. Phypers B, Pierce JT: Lactate physiology in health and disease. Contin Educ Anaesth Crit Care Pa 2006, 6(3):128-132.

6. Shi-Wei H, Jun-Kai K, Chun-Ying W, Sin-Ting W, Hsin-Chen L, Shu-Mei L, Yi-Ju C, Jeng-Jer S: Targeting aerobic glycolysis and HIF-1alpha expression enhance imiquimod-induced apoptosis in cancer cells. Oncotarget 2014, 5(5):1363-1381.

7. Liu X, Zhao H, Jin Q, You W, Cheng H, Liu Y, Song E, Liu G, Tan X, Zhang X: Resveratrol induces apoptosis and inhibits adipogenesis by stimulating the SIRT1-AMPKa-FOX01 signalling pathway in bovine intramuscular adipocytes. Mol Cell Biochem 2018, 439(1-2):213-223.

8. Albina J E, Cui S, Mateo R B, S RJ: Nitric oxide-mediated apoptosis in murine peritoneal macrophages. J Immunol 1993, 150:5080-5085.

9. Kok SH, Hou KL, Hong CY, Chao LH, Lai HH, Wang HW, Yang H, Shun CT, Wang JS, Lin SK: Sirtuin 6 Modulates Hypoxia-induced Apoptosis inOsteoblasts via Inhibition of Glycolysis: 
ImplicationforPathogenesis of Periapical Lesions. J Endodont 2015, 41(10):1631-1637.

10. Ucker DS: Exploiting death: apoptotic immunity in microbial pathogenesis. Cell Death Differ 2016, 23:990-996.

11. Sanman LE, Qian Y, Eisele NA, Ng TM, Wa VDL, Monack DM, Weerapana E, Bogyo M: Disruption of glycolytic flux is a signal for inflammasome signaling and pyroptotic cell death. Elife 2016, 5:e13663.

12. Bowden SD, Gary R, Hinton JCD, Arthur T: Glucose and glycolysis are required for the successful infection of macrophages and mice by Salmonella enterica serovar typhimurium. Infect Immun 2009, 77(7):3117-3126.

13. Jennings E, TIm T, Holden DW: Salmonella SPI-2 Type III Secretion System Effectors: Molecular Mechanisms And Physiological Consequences. Cell Host Microbe 2017, 22(2):217-231.

14. Ochman $\mathrm{H}$, Soncini $\mathrm{F} \mathrm{C}$, Solomon $\mathrm{F}$, Groisman $\mathrm{E}$ A: Identification of a pathogenicity island required for Salmonella survival in host cells. Proc Natl Acad Sci U S A 1996, 93(15):7800-7804.

15. Hensel M, Shea J E, Gleeson C, Jones M D, Dalton E, Holden DW: Simultaneous identification of bacterial virulence genes by negative selection. Science 1995, 269(5222):400-403.

16. Yang Z, Soderholm A, Lung TWF, Giogha C, Hill MM, Brown NF, Hartland E, Teasdale RD: SseK3 Is a Salmonella Effector That Binds TRIM32 and Modulates the Host's NF-KB Signalling Activity. PLOS One 2015, 10(9):e0138529.

17. Esposito D, Günster RA, Martino L, El KO, Wagner A, Thurston T, Rittinger K: Structural basis for the glycosyltransferase activity of the Salmonella effector SseK3. J Biol Chem 2018, 293(14):5064-5078.

18. Brown NF, Coombes BK, Bishop JL, Wickham ME, Lowden MJ, Gal-Mor O, Goode DL, Boyle EC, Sanderson KL, Finlay BB: Salmonella Phage ST64B Encodes a Member of the SseK/NleB Effector Family. PLoS One 2011, 6(3):e17824.

19. Zhang $H$, Yong $H$, Qian D, Luo X, Liang Z, Zhao X, Tong D: Porcine parvovirus infection induces apoptosis in PK-15 cells through activation of p53 and mitochondria-mediated pathway. Biochem Bioph Res Co 2015, 456(2):649-655.

20. He J, Wang C, Sun Y, Lu B, Cui J, Dong N, Zhang M, Liu Y, Yu B: Exendin-4 protects bone marrowderived mesenchymal stem cells against oxygen/glucose and serum deprivation-induced apoptosis through the activation of the CAMP/PKA signaling pathway and the attenuation of ER stress. Int $J$ Mol Med 2016, 37(4):889-900.

21. Ding L, Huang Y, Du Q, Dong F, Zhao X, Zhang W, Xu X, Tong D: TGEV nucleocapsid protein induces cell cycle arrest and apoptosis through activation of p53 signaling. Biochem Bioph Res Co 2014, 445(2):497-503.

22. Wang G, Xu Z, Wang C, Yao F, Li J, Chen C, Sun S: Differential phosphofructokinase-1 isoenzyme patterns associated with glycolytic efficiency in human breast cancer and paracancer tissues. Oncol Lett 2013, 6(6):1701-1706.

23. Chen D, Liao Y, Xu Q, Li Y, Wu W, Wu J, Liao W, Xu D, Liu Y, Wu P: Persistence of systolic and diastolic regional dysfunction after brief episodes of myocardial ischemia evaluated with velocity vector 
imaging. Int j Cardiol 2013, 167(3):987-994.

24. Jia Y, Cong R, Li R, Yang X, Sun Q, Parvizi N, Zhao R: Maternal low-protein diet induces genderdependent changes in epigenetic regulation of the glucose-6-phosphatase gene in newborn piglet liver. J Nutr 2012, 142(9):1659-1665.

25. Ibarra JA, Steele-Mortimer O: Salmonella âه⿴囗十 the ultimate insider. Salmonella virulence factors that modulate intracellular survival. Cell Microbiol 2010, 11(11):1579-1586.

26. Günster RA, Matthews SA, Holden DW, Thurston TL: SseK1 and SseK3 T3SS effectors inhibit NF-KB signalling and necroptotic cell death in Salmonella-infected macrophages. Infect Immun 2017, 85(3):e00010-00017.

27. Kujat Choy SL, Boyle EC, Gal-Mor O, Goode DL, Valdez Y, Vallance BA, Finlay BB: SseK1 and SseK2 are novel translocated proteins of Salmonella enterica serovar Typhimurium. Infect Immun 2004, 72(9):5115-5125.

28. Mcintosh A, Meikle LM, Ormsby MJ, Mccormick BA, Christie JM, Brewer JM, Roberts M, Wall DM: SipA Activation of Caspase-3 Is a Decisive Mediator of Host Cell Survival at Early Stages of Salmonella enterica Serovar Typhimurium Infection. Infect Immun 2017, 85(9):e00393-00417.

29. He P, Wu S, Chu Y, Yang Y, Li Y, Huang R: Salmonella enterica serovar Typhi plasmid pR ST98 enhances intracellular bacterial growth and $\mathrm{S}$. typhi -induced macrophage cell death by suppressing autophagy. Braz J Infect Dis 2012, 16(3):262-266.

30. Newson JPM, Scott NE, Chung IYW, Lung TWF, Giogha C, Gan J, Wang N, Strugnell RA, Brown NF, Cygler M et al: Salmonella Effectors SseK1 and SseK3 Target Death Domain Proteins in the TNF and TRAIL Signaling Pathways. Mol Cell Proteomics 2019, 18(6):1138-1156.

31. Santos R L, Tsolis R M, Bäumler A J, Smith R, Adams L G: Salmonella enterica serovar typhimurium induces cell death in bovine monocyte-derived macrophages by early sipB-dependent and delayed sipB-independent mechanisms. Infect Immun 2001, 69(4):2293-2301.

32. Kasinskas RW, Forbes N: Salmonella typhimurium lacking ribose chemoreceptors localize in tumor quiescence and induce apoptosis. Cancer Res 2007, 67(7):3201-3209.

33. Ding K, Zhang C, Li J, Chen S, Liao C, Cheng X, Yu C, Yu Z, Jia Y: cAMP Receptor Protein of Salmonella enterica Serovar Typhimurium Modulate Glycolysis in Macrophages to Induce Cell Apoptosis. Curr Microbiol 2019, 76(1):1-6.

34. Gulati A, Shukla R, Mukhopadhaya A: Salmonella Effector SteA Suppresses Proinflammatory Responses of the Host by Interfering With IkappaB Degradation. Front Immuno/ 2019, 10:2822.

35. Mcintosh A, Meikle LM, Ormsby MJ, Mccormick BA, Wall DM: SipA activation of caspase-3 is a decisive mediator of host cell survival at early stages of Salmonella enterica serovar typhimurium Infection. Infect Immun 2017, 85(9):IAl.00393-00417.

36. Luo F, Sun X, Qu Z, Zhang X: Salmonella typhimurium-induced M1 macrophage polarization is dependent on the bacterial 0 antigen. World J Microbiol Biotechnol 2016, 32(2):22.

37. Wei Y, Kong B, Song K, Qu X, Jin Q, Yang Q: Involvement of mitochondria-caspase pathway in Hemoporfin-mediated cell death. Photochem Photobio/ 2010, 83(6):1319-1324. 
38. Knodler L A, Finlay B B, O S-M: The Salmonella effector protein SopB protects epithelial cells from apoptosis by sustained activation of Akt. J Biol Chem 2005, 280(10):9058-9064.

39. Hans HC, Christine F, Hermann W, Georg HC: Caspase-9/-3 activation and apoptosis are induced in mouse macrophages upon ingestion and digestion of Escherichia coli bacteria. J Immunol 2002, 169(6):3172-3179.

40. Ming MS, Panagiotis T, Lee H, Monie TP, Fitzgerald KA, Bryant CE: Salmonella infection induces recruitment of Caspase- 8 to the inflammasome to modulate IL-1 $\beta$ production. $J$ Immuno/ 2013, 191(10):5239-5246.

41. Comin-Anduix B, Boros L G, Marin S, Boren J, Callol-Massot C, Centelles JJ, Torres JL, Agell N, Bassilian S, Cascante M: Fermented wheat germ extract inhibits glycolysis/pentose cycle enzymes and induces apoptosis through poly(ADP-ribose) polymerase activation in Jurkat T-cell leukemia tumor cells. J Biol Chem 2002, 277(48):46408-46414.

42. Jeong D W, Kim T S, Cho I T, Y KI: Modification of glycolysis affects cell sensitivity to apoptosis induced by oxidative stress and mediated by mitochondria. Biochem Bioph Res Co 2004, 313(4):984991.

43. Zhu Y, Ramos da Silva S, He M, Liang Q, Lu C, Feng P, Jung JU, Gao SJ: An Oncogenic Virus Promotes Cell Survival and Cellular Transformation by Suppressing Glycolysis. PLoS Pathog 2016, 12(5):e1005648.

44. Li J, Chen K, Wang F, Dai W, Li S, Feng J, Wu L, Liu T, Xu S, Xia Y: Methyl jasmonate leads to necrosis and apoptosis in hepatocellular carcinoma cells via inhibition of glycolysis and represses tumor growth in mice. Oncotarget 2017, 8(28):45965-45980.

45. Sumi C, Okamoto A, Tanaka H, Nishi K, Kusunoki M, Shoji T, Uba T, Matsuo Y, Adachi T, Hayashi JI: Propofol induces a metabolic switch to glycolysis and cell death in a mitochondrial electron transport chain-dependent manner. PLoS One 2018, 13(2):e0192796.

46. Merlin TY, Leatham MP, Allen JH, Laux DC, Tyrrell C, Cohen PS: Role of gluconeogenesis and the tricarboxylic acid cycle in the virulence of Salmonella enterica serovar Typhimurium in BALB/c mice. Infect Immun 2006, 74(2):1130-1140.

47. Lecarpentier $Y$, Claes $V$, Vallée $A$, Hébert JL: Thermodynamics in cancers: opposing interactions between PPAR gamma and the canonical WNT/beta-catenin pathway. Clin Trans/ Med, 2017, 6(14):1-11.

48. Mickelson MN: Glucose Degradation, MolarGrowthYields, and Evidence forOxidative Phosphorylation in Streptococcus agalactiae. J Bacterio/ 1972, 109(1):96-105.

49. Zhou J, Li C, Yao W, Alsiddig MC, Huo L, Liu H, Miao YL: Hypoxia-inducible factor-1a-dependent autophagy plays a role in glycolysis switch in mouse granulosa cells. Biol Reprod 2018, 99(2):308318.

50. Gill K, Fernandes P, O'Donovan T, McKenna S, Doddakula K, Power D, Soden D, Forde P: Glycolysis inhibition as a cancer treatment and its role in an anti-tumour immune response. Biochimica et biophysica acta 2016, 1866(1):87-105. 
51. Ma Z, Yan H, Wang Y, Yang Y, Li X, Shi A, Jing-Wen X, Yu-Bao L, Li L, Wang X: Proteomics analysis demonstrating rosmarinic acid suppresses cell growth by blocking the glycolytic pathway in human HepG2 cells. Biomed Pharmacother 2018, 105:334-349.

52. Lin Y, Lee B, Liu P, Wei L: Receptor-Interacting Protein 140 Orchestrates the Dynamics of Macrophage M1/M2 Polarization. Journal of innate immunity 2016, 8(1):97-107.

53. Ye Y, Xu Y, Lai Y, He W, Li Y, Wang R, Luo X, Chen R, Chen T: Long non-coding RNA cox-2 prevents immune evasion and metastasis of hepatocellular carcinoma by altering M1/M2 macrophage polarization. J Cell Biochem 2018, 119(3):2951-2963.

54. Shi Y, Guo X, Zhang J, Zhou H, Sun B, Feng J: DNA binding protein HMGB1 secreted by activated microglia promotes the apoptosis of hippocampal neurons in diabetes complicated with OSA. Brain Behav Immun 2018, 73:482-492.

55. Liu L, Lu Y, Martinez J, Bi Y, Lian G, Wang T, Milasta S, Wang J, Yang M, Liu G et al: Proinflammatory signal suppresses proliferation and shifts macrophage metabolism from Myc-dependent to HIF1adependent. Proc Natl Acad Sci U S A 2016, 113(6):1564-1569.

56. Shippy DC, Eakley NM, Bochsler PN, Fadl AA: Biological and virulence characteristics of Salmonella enterica serovar Typhimurium following deletion of glucose-inhibited division ( gidA) gene. Microb Pathog 2011, 50(6):303-313.

57. Yang Y, Yu C, Ding K, Zhang C, Liao C, Jia Y, Li J, Cheng X: Role of the sseK1 gene in the pathogenicity of Salmonella enterica serovar enteritidis in vitro and in vivo. Microb Pathog 2018, 117(117): 270-275.

\section{Additional File Legends}

Additional file: the ARRIVE Guidelines checklist

Supplementary Fig. 1 Adherence and invasion assays for WT, $\Delta$ sseK3 mutant, and sseK3-complemented strains in RAW264.7 cells. Bonferroni's multiple-comparison test showed no significant differences between the groups $(P>0.05)$.

\section{Figures}


A

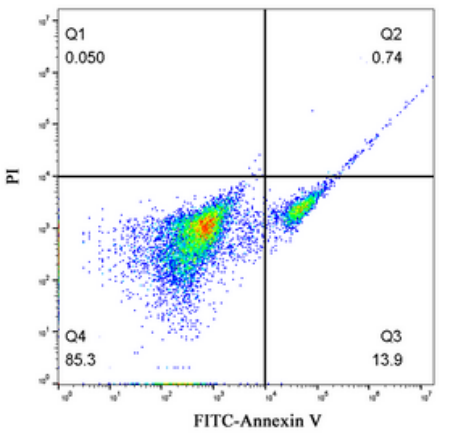

WT

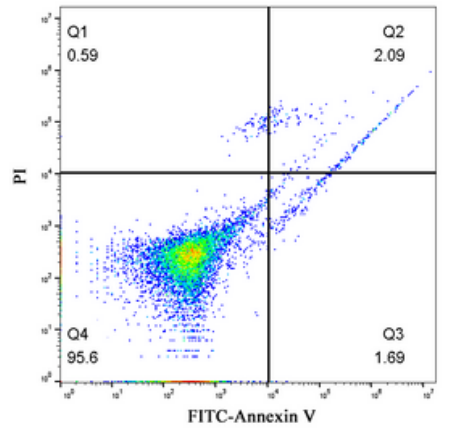

$\Delta$ sseK3

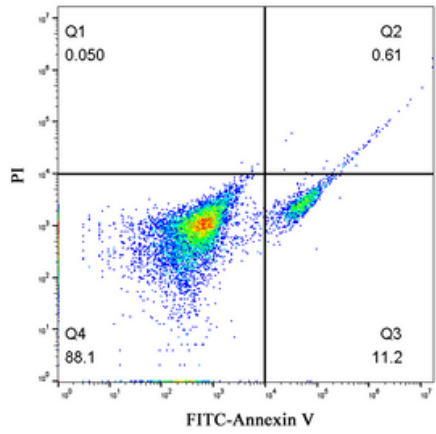

Complemented

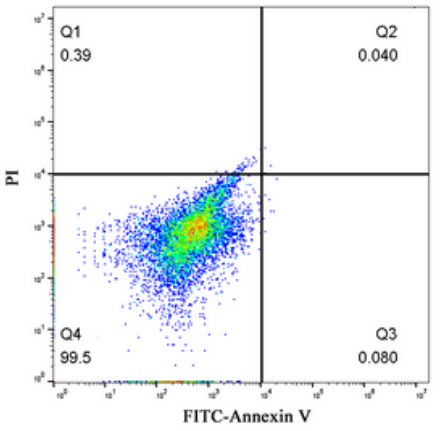

Mock

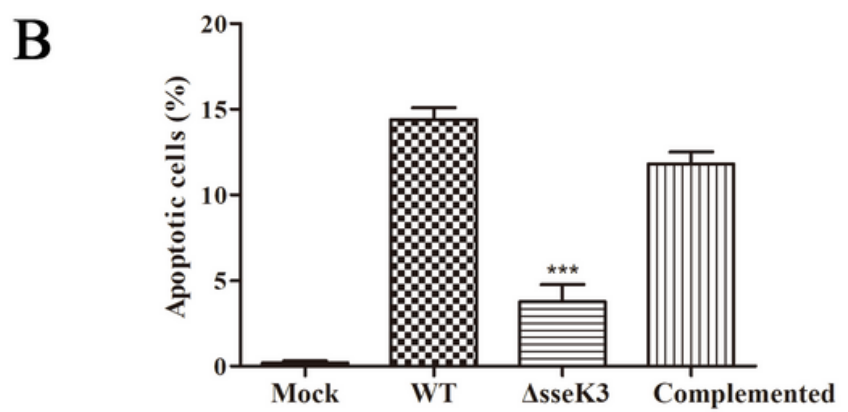

Figure 1

Flow cytometric analysis of apoptosis in RAW264.1 macrophages infected with WT S. Typhimurium, $\triangle$ sseK3 mutant, or complemented strains. RAW264.1 macrophages were incubated for $4 \mathrm{~h}$ with WT S. Typhimurium, $\Delta$ sseK3 mutant, or sseK3 complemented strains. Apoptosis was assessed using Annexin V-FITC/PI double staining. (A) Representative dot plots showing Annexin V-FITC /PI staining. The upper left quadrant (Q1) contains the necrotic(Annexin V-FITC-/PI+) population, the upper right quadrant (Q2) contains the late apoptotic (Annexin V-FITC+/PI+) population, and the lower right quadrant (Q3) contains the early apoptotic (Annexin V-FITC+/PI-) population. The lower left quadrant (Q4) contains the healthy (double negative) population. (B) Percentage of apoptosis in cells exposed to different bacteria determined by flow cytometric analysis. After $4 \mathrm{~h}$ of incubation, the apoptosis rate in the $\Delta$ sseK3 mutant group was significantly lower than that in the WT and sseK3-complemented groups ( $\left.{ }^{* \star} P<0.001\right)$. Data from three independent experiments were used to determine percentage of apoptotic cells. Error bars indicate the SD from three independent experiments. 

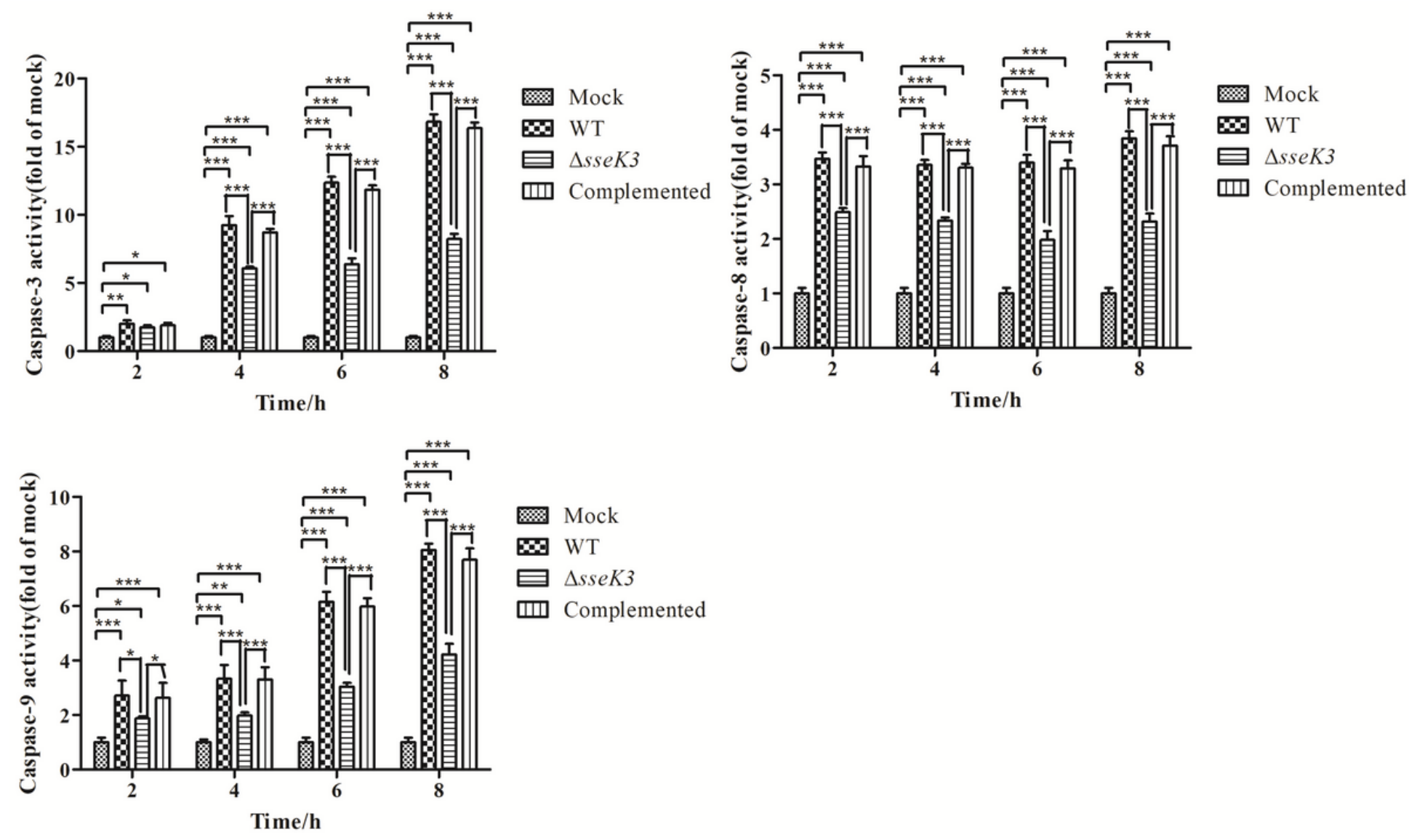

Figure 2

Caspase-3, caspase-8, and caspase-9 activity in RAW264.7 cells infected with WT S. Typhimurium, $\Delta$ sseK3 mutant, or sseK3-complemented strains. Caspase-3, -8 , and -9 activity was measured by colorimetric assay and analyzed using two-way ANOVA with Bonferroni's multiple-comparison test ( ${ }^{*}<$ 0.05 , $\left.{ }^{\star \star} P<0.01,{ }^{\star \star \star} P<0.001\right)$. Results are shown as mean $\pm S D$. 

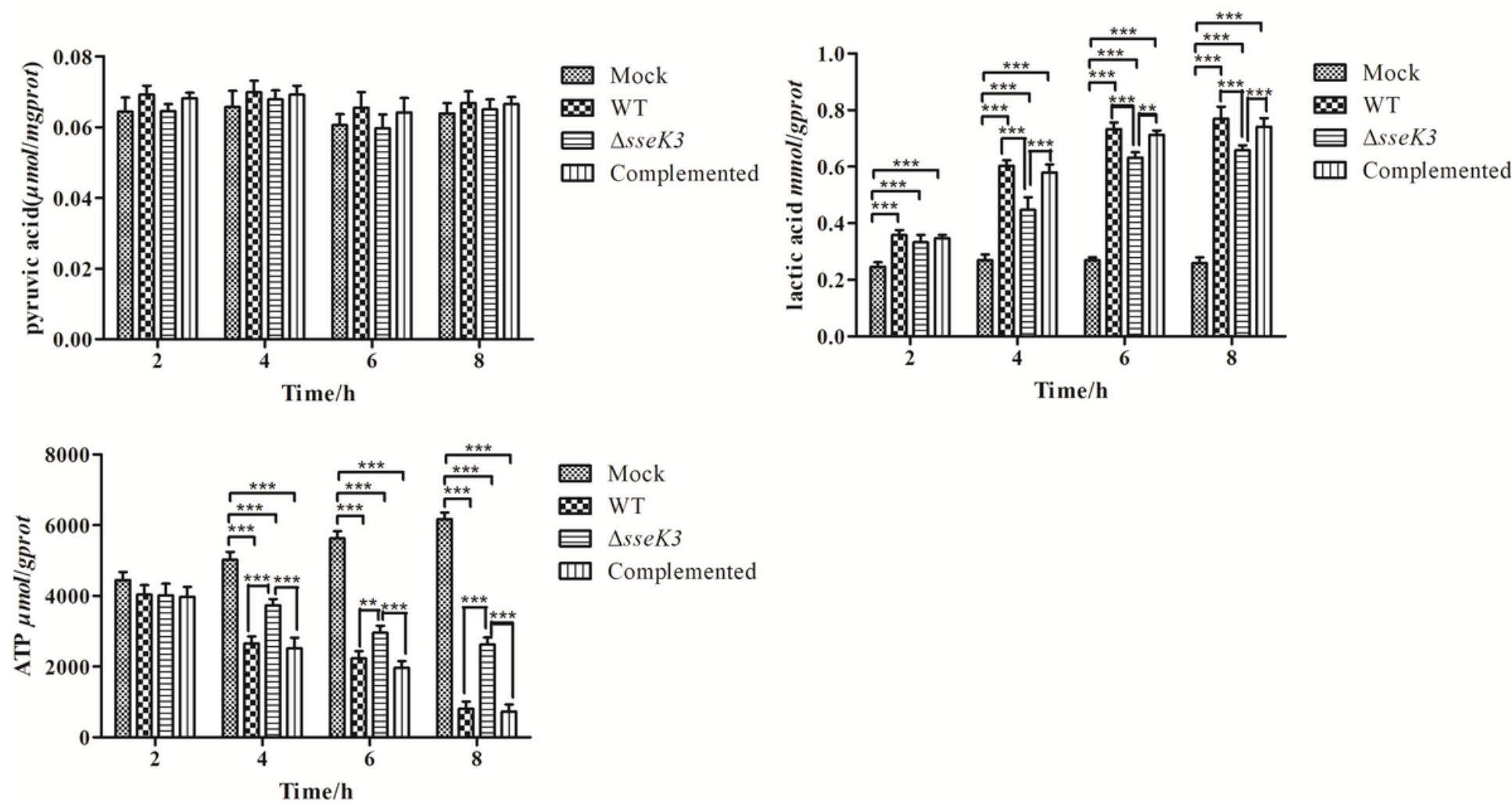

Figure 3

Glycolysis in RAW264.7 cells infected with WT, $\Delta$ sseK3 mutant, or sseK3-complemented strains. The pyruvic acid, lactic acid, and ATP levels were measured by colorimetric assay and analyzed using twoway ANOVA with Bonferroni's multiple-comparison test $\left({ }^{\star} P<0.05,{ }^{\star \star} P<0.01,{ }^{\star \star \star *} P<0.001\right)$. Results are shown as mean \pm SD.

\section{Supplementary Files}

This is a list of supplementary files associated with this preprint. Click to download.

- SupplementaryFigure1.jpg 